\title{
Correction to: Networked Religion: Metaphysical Redemption or Eternal Regret?
}

Peter McLaren ${ }^{1,2}$

Published online: 12 May 2020

(C) Springer Nature Switzerland AG 2020

\section{Correction: Postdigital Science and Education \\ https://doi.org/10.1007/s42438-020-00112-9}

The article was published with a missing paragraph. Thus, this erratum is presented to fix this error.

The original article has been corrected.

The online version of the original article can be found at https://doi.org/10.1007/s42438-020-00112-9

\section{Peter McLaren \\ peter.mclaren1@gmail.com}

1 Chapman University, Orange, CA, USA

2 Northeast Normal University, Changchun, China 